\title{
A generally applicable validation scheme for the assessment of factors involved in reproducibility and quality of DNA-microarray
} data

\author{
Sacha AFT van Hijum ${ }^{1}$, Anne de Jong ${ }^{1}$, Richard JS Baerends ${ }^{1}$, \\ Harma A Karsens ${ }^{1}$, Naomi E Kramer ${ }^{1}$, Rasmus Larsen ${ }^{1}$, Chris D den Hengst ${ }^{1}$, \\ Casper J Albers ${ }^{2}$, Jan Kok ${ }^{1}$ and Oscar P Kuipers*1
}

Address: ${ }^{1}$ Department of Molecular Genetics, University of Groningen, Groningen Biomolecular Sciences and Biotechnology Institute, PO Box 14 , 9750 AA Haren, the Netherlands and ${ }^{2}$ Groningen Bioinformatics Centre, University of Groningen, Groningen Biomolecular Sciences and Biotechnology Institute, PO Box 14, 9750 AA Haren, the Netherlands

Email: Sacha AFT van Hijum - s.a.f.t.van.hijum@rug.nl; Anne de Jong - anne.de.jong@rug.nl; Richard JS Baerends - r.j.s.baerends@rug.nl; Harma A Karsens - h.a.karsens@rug.nl; Naomi E Kramer - mrskramernaomi@yahoo.com; Rasmus Larsen - r.larsen@rug.nl; Chris D den Hengst - c.d.den.hengst@rug.nl; Casper J Albers - c.j.albers@rug.nl; Jan Kok - jan.kok@rug.nl; Oscar P Kuipers* - o.p.kuipers@rug.nl

* Corresponding author

Published: 20 May 2005

BMC Genomics 2005, 6:77 doi:I0.1 I86/147|-2/64-6-77
Received: 0I November 2004

Accepted: 20 May 2005

This article is available from: http://www.biomedcentral.com/I47I-2/64/6/77

(C) 2005 van Hijum et al; licensee BioMed Central Ltd.

This is an Open Access article distributed under the terms of the Creative Commons Attribution License (http://creativecommons.org/licenses/by/2.0), which permits unrestricted use, distribution, and reproduction in any medium, provided the original work is properly cited.

\begin{abstract}
Background: In research laboratories using DNA-microarrays, usually a number of researchers perform experiments, each generating possible sources of error. There is a need for a quick and robust method to assess data quality and sources of errors in DNA-microarray experiments. To this end, a novel and cost-effective validation scheme was devised, implemented, and employed.

Results: A number of validation experiments were performed on Lactococcus lactis ILI403 amplicon-based DNA-microarrays. Using the validation scheme and ANOVA, the factors contributing to the variance in normalized DNA-microarray data were estimated. Day-to-day as well as experimenter-dependent variances were shown to contribute strongly to the variance, while dye and culturing had a relatively modest contribution to the variance.

Conclusion: Even in cases where $90 \%$ of the data were kept for analysis and the experiments were performed under challenging conditions (e.g. on different days), the CV was at an acceptable $25 \%$. Clustering experiments showed that trends can be reliably detected also from genes with very low expression levels. The validation scheme thus allows determining conditions that could be improved to yield even higher DNA-microarray data quality.
\end{abstract}

\section{Background}

The development of DNA-microarray technology has enabled genome-wide expression profiling to become a valuable tool in the investigation of an organisms' gene regulation [1-3]. For our studies on gene regulation in Gram-positive bacteria [4] we use in-house developed
DNA-microarrays containing amplified DNA fragments of the annotated genes of Lactococcus lactis ssp. lactis IL1403 [5], L. lactis ssp. cremoris MG1363 [6], Bacillus subtilis 168 [7], Bacillus cereus ATCC 14579 [8], and Streptococcus pneumoniae TIGR4 [9]. 


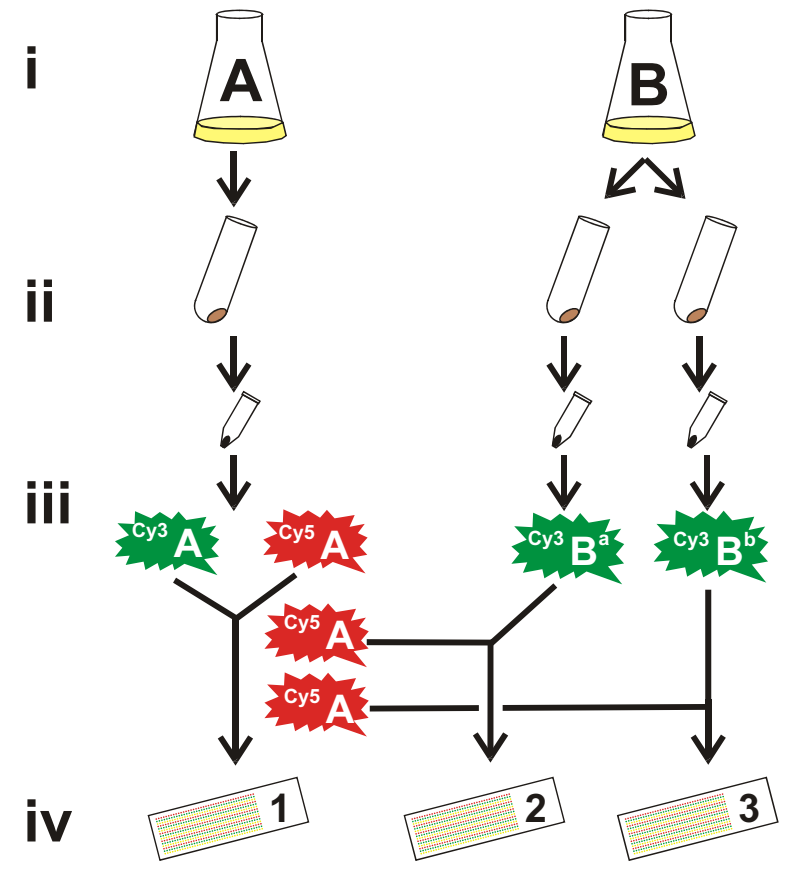

Figure I

The validation procedure. It consists of 4 steps: (i) cell culturing, (ii) cell pelleting and RNA isolation, (iii) cDNA labeling, and (iv) hybridization, scanning, image- and data analysis.

Standardization of every step in the DNA-microarray procedure is crucial to correctly and efficiently perform DNAmicroarray experiments, and to obtain reproducible data [10-13]. In the process from manufacturing DNA-microarrays to performing the actual experiments, systematic errors and / or bias in the data are introduced in each of the different steps. The effects of various factors (e.g. dye and slide) on the quality of DNA-microarray data have been studied quite extensively albeit for experiments performed with eukaryotic systems [14-20]. In contrast, no data quality determination has yet been performed on DNA-microarray data from experiments with bacterial cultures. Furthermore, the effects of different array batches or the influence of the experimenter on data quality have not been included in the previous mentioned experimental designs. Here, we show that the latter factors are indeed important for optimizing DNA-microarray data quality.

In order to assess the reproducibility of, and factors involved in, DNA-microarray data produced in our laboratory during transcriptome analyses by a number of researchers, a validation experiment was designed and implemented. This validation scheme is routinely applied
Table I: General statistics on data obtained from the validation experiments (Figure $I$ and supplementary Table $S I$ [2I]).

\begin{tabular}{|c|c|c|c|c|c|c|}
\hline \multirow[t]{2}{*}{ Validation } & \multicolumn{3}{|c|}{ Validation slide } & \multicolumn{2}{|c|}{$5 \%$ low spot filter } & \multirow[t]{2}{*}{$40 \%$ low spot filter } \\
\hline & I & 2 & 3 & CV (\%) & Spots (\%) & \\
\hline$A-I$ & $x$ & $x$ & $x$ & 27.3 & 89.5 & 17.4 \\
\hline A-I & $x$ & & & 21.6 & 88.7 & 13.4 \\
\hline A-I & & $x$ & & 26.1 & 88.9 & 17.3 \\
\hline A-I & & & $x$ & 24.6 & 91.1 & 16.5 \\
\hline A & $x$ & $x$ & $x$ & 16.4 & 86 & 12.5 \\
\hline B & $x$ & $x$ & $x$ & 13 & 84.3 & 9.4 \\
\hline C & $x$ & $x$ & $x$ & 14 & 94.5 & 8.6 \\
\hline D & $x$ & $x$ & $x$ & 16.7 & 92.1 & 11.1 \\
\hline $\mathrm{E}$ & $x$ & $x$ & $x$ & 9.2 & 90.4 & 6.7 \\
\hline$F$ & $x$ & $x$ & $x$ & 27.5 & 87.3 & 20.2 \\
\hline G & $x$ & $x$ & $x$ & 16.5 & 88.5 & 10.3 \\
\hline $\mathrm{H}$ & $x$ & $x$ & $x$ & 23.8 & 91 & 15.1 \\
\hline I & $x$ & $x$ & $x$ & 18.1 & 92.2 & 12.4 \\
\hline
\end{tabular}

to validate the DNA-microarrays of the various organisms under study in our group. In addition, it allowed to set a quality standard as well as to assess sources of errors in the expression data.

We discuss a novel validation scheme and assess data quality of a number of validation experiments performed on amplicon-based DNA-microarrays of L. lactis IL1403. For any laboratory in which DNA-microarray experiments are performed on a regular basis, the validation scheme will provide at the cost of only a few hybridizations, valuable information on the DNA-microarray data quality. Combining multiple validation experiments allows estimation of the main sources of errors.

\section{Results \\ DNA-microarray quality assessment}

Six researchers working with L. lactis IL1403 slides performed nine validation experiments (see Methods and Figure 1). General statistics on these validation datasets are listed in Table 1. One has to bear in mind that DNAmicroarrays with lower signals will yield more noisy data, and thus higher coefficients of variance (CVs). Since these lower signals might also contain valuable information, they are included in the analyses described here.

\section{No differentially expressed genes were detected}

Differential expression tests were performed for the factors (supplementary Table S1 [21]; e.g. spot-pins, experimenters, and validation experiments), but no genes 
meeting the criteria were observed. No differential expression was expected because the hybridizations were performed with cDNA derived from cells grown under (very) similar conditions. The resulting expression ratios were thus close to 1 .

\section{CV comparison}

The CVs of the validation experiments range from $9 \%$ to $28 \%$ with an average of $17 \%$ and using about $90 \%$ of the spots. The lower CVs of the $40 \%$ low-intensity-spot-filtered data (Table 1) indicate that a significant part of the variance originates from genes with low expression. Slides 2 and 3 of each validation experiment (S2 and S3, respectively) examine biological replicates of independent comparisons between the cultures A and B (Figure 1). Their data quality is thus a "worst case scenario" estimate of the quality to be expected from "real" DNA-microarray experiments as the validation experiments were performed with a large number of differing parameters: (i) different researchers performed the experiments, (ii) on different days, while, lastly, (iii) the cells were harvested in a growth phase in which small changes in culture optical density will result in relatively large differences in expression levels (see below). Table 1 shows, as expected, that data from the pooled slides 1 of all validation experiments (S1) have a smaller average CV (22\%) than those of S2 (26\%) and S3 (25\%). The CV frequency distribution for S1 is shifted towards zero while S2 and S3 have quite similar distributions (supplementary Figure S1 [21]) because of intra-culture differences ( $\mathrm{B}^{\mathrm{a}}$ or $\mathrm{B}^{\mathrm{b}}$; Figure 1).

\section{Detailed comparison of two slides}

The two representative validation experiments, i.e. E and $\mathrm{H}$, showed clear differences in data quality (supplementary Table S1 [21]). Box plots of data before the Lowess grid-based normalization show clear spot pin-dependent patterns in average signal levels (supplementary Figure S2 [21]). A non-linear intensity-dependent dye-effect in data from slide E3 (supplementary Figure S2 [21], Graph E2, (i) is evident from the curved Lowess fits. The Lowess curves (one curve fitted for each spotted grid; supplementary Figure S2 [21]) (ii) of slides E3 and H2 are "stacked", indicative of a grid-dependent gradient of ratios. The above-mentioned effects are normalized by using the Lowess grid-based normalization method (supplementary Figure S2 [21], Graph V).

\section{Gene-dependent fluctuations in ratios and signals}

Clustering was performed on the SDs of the ratio-data to investigate gene-dependent behavior across the validation experiments (Figure 2). Cluster 1 contains more strongly expressed genes than cluster 4, with clusters 2 and 3 encompassing genes with intermediate expression levels.

\section{The clustering results were simplified by grouping genes}

A first selection of genes was based on the L. lactis IL1403 genome annotation with the underlying assumption that related genes (either by function or because they are part of the same operon) are expected to show similar expression behavior. Only related genes with all members occurring in the same cluster (probability lower than 0.02) were considered.

\section{Cell growth-related genes show large fluctuations}

Clustering revealed that genes with similar SD fluctuations were involved in (i) amino acid biosynthesis, (ii) energy metabolism, (iii) cell-wall synthesis, and (iv) salvage of nucleosides and nucleotides (Figure 2). Genes showing highest ratio and signal CVs (supplementary Table S2 [21]): (i) are of unknown function, (ii) are (pro) phage-derived, (iii) encode proteins involved in transport of various compounds, or (iv) encode transcriptional regulators.

\section{Some genes with low expression show correlated expression fluctuations}

Figure 3 clearly illustrates that (i) the genes with low expression have significantly higher CVs than the highly expressed genes, which is most probably due to their lower signals, and (ii) the related genes (clustered in Figure 3) showing similar expression behavior have average expression levels varying from very low $(1.7 \%$ of the maximum intensity) to relatively high ( $65 \%$ of the maximum intensity). After a close inspection of these (mostly lowintensity) spots, the fluctuations in ratio and / or expression levels did not appear to be correlated to spot quality (data not shown).

\section{ANOVA}

A clear correlation between CVs (data quality) and e.g. array batches or experiments could not be determined. For instance, validation experiments $\mathrm{H}$ and I were performed on the same DNA microarray batch by the same experimenter, but yielded different CVs. The ANOVA technique allowed estimating the contribution of several sources of errors to the total variance in the DNA-microarray data of all slides (Figure $4 ; S=1 \mathrm{v} 2 \mathrm{v} 3$ ). The following factors contributed significantly to the total variance: $G$ (gene; $5 \%$; Table 2), VG (validation experiment and gene interaction; $27 \%$ ), SG (slide and gene interaction indicative for dye-effects; $4 \%$; Table 2), and VSG (validation experiment, slides, and gene interactions; $31 \%$ ).

\section{The VSG interaction detailed}

In order to distinguish the separate sources of errors in the VSG interaction, additional variance analyses were performed with combinations of 2 slides: (i) by omitting slide 1 (S1; containing a self-hybridization) the VSG interaction $(S=2 \mathrm{v} 3)$ decreased with $7.8 \%$; (ii) by omitting 


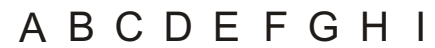

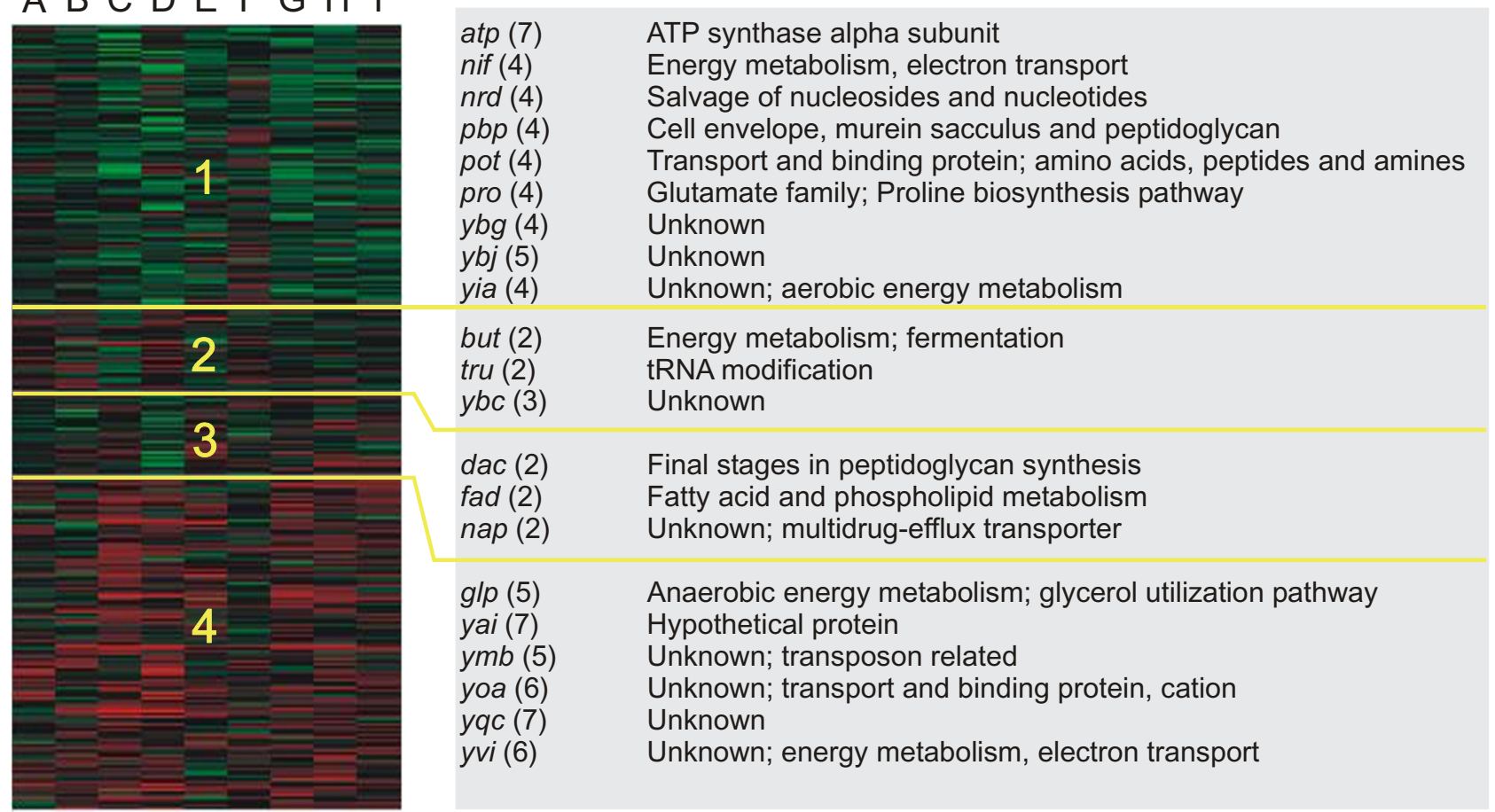

\section{Figure 2}

Sammon projection of the clustering of validation data using a self-organizing Kohonen map. Validation experiments (A-I) are shown as well as the clusters (I - 4; consisting of 76I, 230, 227, 886 genes, respectively). Operon names, the number of members, and their (putative) functions are listed to the right of the corresponding clusters. The minimum number of genes in an operon of which all members should be in a certain cluster was determined at a probability of 0.02 or lower for clusters I (4 genes), 2 (2 genes), 3 ( 2 genes), and 4 (5 genes).

slides 2 or 3 (S2 or S3; containing inter-culturing hybridizations) the VSG interaction ( $S=1 \mathrm{v} 2$ or $S=1 \mathrm{v} 3)$ decreased with $9.4 \%$ and $9.1 \%$, respectively; and (iii) the decrease in the VSG interactions coincides with an increase of the VG interaction. This leads to the conclusion that variances occur on each slide (Gene $x$ Array; Table 2) and may, in part, be due to hybridization effects. Since the variance for a particular slide $(7.8 \%)$ is omitted from the variance analyses, the VSG interaction will decrease, but the VG interaction will increase (the 7.8 $\%$ variance was specific for the slide that was omitted from the analyses). This $7.8 \%$ variance is assumed to be the same for each of the three slides. The larger effect of S2 and S3 compared to S1 in the VSG interaction is probably caused by the fact that on these slides inter-culture comparisons were performed. Since dye-effects are assumed to be global, it can be concluded that the intra-culturing differences (differences between the $\mathrm{B}^{\mathrm{a}}$ and $\mathrm{B}^{\mathrm{b}}$ cultures) account for the 1.6 and $1.3 \%$ larger decrease in the VSG interaction (by omitting S2 or S3, respectively). The vari- ance introduced by the $\mathrm{B}^{\mathrm{a}}$ and $\mathrm{B}^{\mathrm{b}}$ cultures is quite reproducible $(1.3-1.6 \%)$ and is caused by RNA isolation and labeling (Table 2).

Slide and sampling differences can be determined from VSG The variance of S1 versus the pooled S2 and S3 ( $S=1 \mathrm{v} 23)$ in the VSG interaction decreased with $16.1 \%$ to $14.9 \%$, with the variance in the VG interaction remaining virtually unchanged. By combining S2 and S3, the Gene $x$ Array interactions occurring specifically on S2 and S3 are pooled. They are, thus, not accommodated in the VG interaction, but rather in the residual error. The remaining $14.9 \%$ variance in the VSG interaction still contains the Gene $\times$ Array interactions for S1 (7.8\%) and sampling differences $(7.1 \%$; Table 2$)$.

\section{Day-to-day differences are most prominent in the VG interaction}

The VG interaction contains differences between validation experiments (Figure 4): the DNA microarray batch used $(B G)$, day-to-day differences $(A G)$, the researcher 


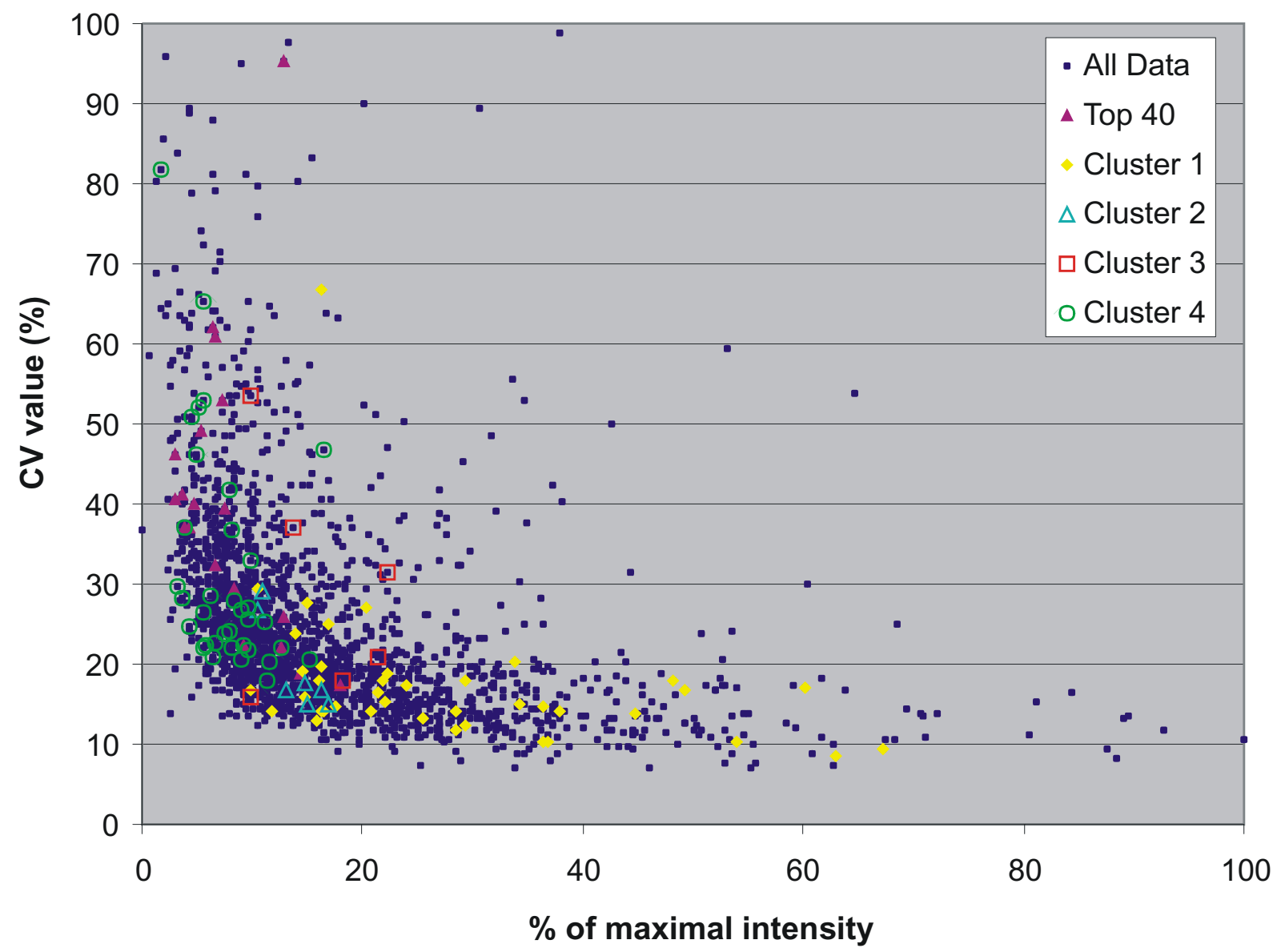

Figure 3

Plot of percentage of maximal intensity versus CV values calculated for the expression levels of genes in the 9 validation datasets (dark-blue small squares). Purple solid triangles show the top 40 genes with highest variability in ratio and signals (supplementary Table S2 [2I]). Functionally related genes showing validation experiment-dependent SDs (Figure 2) are indicated by cluster I (solid yellow circles), cluster 2 (open light-blue triangles), cluster 3 (open red squares), and cluster 4 (open green circles).

performing the experiment $(P G)$, and spot-pin / RNA isolation method used $(D U)$. Due to confounding of these factors, a less efficient estimation of their relative contributions was unavoidable. However, the contributions of $B G, P G, A G, D U$ in relation to the $V G$ interaction could be determined (Table 2). The day-to-day differences were estimated to have the largest contribution to the variance, followed by experimenter, the DNA microarray batch, and lastly a relatively low contribution of switching the RNA isolation method (coinciding with a change from 8 to 12 spot-pins).

\section{Discussion}

The validation procedure presented here was implemented to provide a standardized method to assess DNAmicroarray data quality generated in our laboratory and should be well-suited for use in other laboratories. A workable trade-off between costs, time investment, and data-quality was obtained by using only three DNAmicroarray slides for each validation experiment. This scheme is suitable for identifying factors that yield "unreliable" data (i.e. data with ratios that deviate from 1 due to, for instance, outliers). In a number of cases, the 


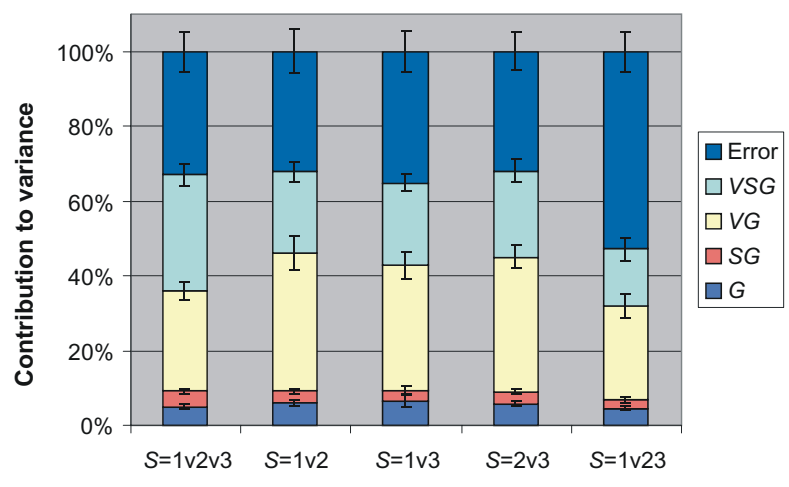

Figure 4

ANOVA results. Each bar represents averages (with error bars signifying the standard deviations for the respective interactions) for 10 random samples of ratio data obtained for the indicated slide combinations (I, 2, and 3; Figure I). E.g. $S=$ I 2 indicates a comparison of data from slides I with data from slides 2 . The interactions (indicated by the colored bars as detailed in the inset) and "Error" (residual variance) amount to $100 \%$ (the total variance present in the data).

Table 2: Contribution of sources to the variance estimated for the nine validation experiments (Figure 4) and contribution of individual factors to the VG interaction ${ }^{a}$.

\begin{tabular}{|c|c|}
\hline Variance source & Contribution to the variance (\%) \\
\hline Gene $(G)$ & 5.0 \\
\hline Dye (SG) & 4.2 \\
\hline Gene $\times$ Arrayb & 7.8 \\
\hline RNA isolation and labelingc & 1.5 \\
\hline Sampling & 7.1 \\
\hline$V G^{d}$ & 26.9 \\
\hline Day $\times$ Gene & $19.7 \mathrm{e}$ \\
\hline Experimenter $\times$ Gene & $17.3 \mathrm{e}$ \\
\hline Array batch $\times$ Gene & $14.9 \mathrm{e}$ \\
\hline Spot pins $\times$ Gene & $4.5^{f}$ \\
\hline
\end{tabular}

a The degrees of freedom results in the separate ANOVAs are listed in the supplementary web-site [2I].

${ }^{b}$ Assumed to consist of hybridization effects and signal-to-noise differences per slide.

$c$ Derived from the variance observed between $\mathrm{B}^{\mathrm{a}}$ and $\mathrm{B}^{\mathrm{b}}$ cultures (Figure I).

dVariances that are dependent on the validation experiment performed and due to day-to-day differences, identity of the experimenter, and DNA microarray batch differences.

e Due to overlap in levels, the contribution of these interactions were individually determined.

${ }^{f} A$ change from 8 to 12 spot-pins used for array spotting coincided with a switch in the RNA isolation method. validation experiment even identified experimenters who did not flag bad spots stringently enough.

Assessment of high-throughput gene expression data quality is a challenging task. A potential problem arises from the fact that many studies do not describe in detail the resulting amount of data on which statistic analyses was based. This information is, however, crucial to determine data-quality. To demonstrate the effect of filtering on data quality, statistics were also calculated for data in which $40 \%$ of the lowest intensity spots were removed (Table 1). These rigorously filtered data do show improved data quality, but at the expense of many measurements that could contain valuable information. The 5 $\%$ low-intensity spot filter employed in our study was selected after careful examination of data from various DNA-microarray experiments performed in our laboratory. Some targets with low expression levels allowed grouping genes by function, revealing trends that would have been difficult to discern with more rigorous filtering. A thorough discussion of these results is, however, outside the scope of this study.

The data quality of the validation experiments described in this paper proved to be satisfactory, while at same time a maximum amount of data was preserved. One has to bear in mind that a significant part of the variance in our data is caused by varying factors (e.g. differences in the days on which the experiments were performed; discussed in more detail below). In addition, the quality of the glass surfaces used in this study was lower than that of presently used superamine glass slides (Telechem International Inc.). Together with recently implemented increased stringency of clean-room rules, this will increase data-quality even more. The average $\mathrm{CV}$ value for the validation experiments was $26.1 \%$ and $24.6 \%$ for S2 and S3 with use of $90 \%$ of the spots (Table 1 ). These results are comparable to CVs, ranging from 11 to $23 \%$, reported for a number of studies using cDNA derived from eukaryotic cell cultures hybridized on various DNA microarray platforms $[20,22,23]$. For other DNA-microarray experiments performed in our laboratory the data quality is considerably higher (average CVs of under $20 \%$ ) stipulating that in effect, the average CV of about $25 \%$ described in this study is an underestimation of the data quality one could obtain.

By mining the data from several validation datasets it was possible to determine which factors contribute to the variance in normalized DNA-microarray data. The following factors were identified (Figure 4 and Table 2): (i) validation experiments $(V G ; 27 \%)$, (ii) sampling (7\%), (iii) Array $\times$ Gene $(8 \%)$, gene variances $(5 \%)$, and dye-effects $(4 \%)$. The contributions of RNA isolation and labeling to the variance were quite low (1.5\%; Table 2$)$. Additional 
variance analyses showed that the day-to-day differences contribute most to the $27 \%$ variance observed for the VG interaction, followed by the experimenter, the DNA microarray batch, and lastly a change in the RNA isolation method (coinciding with the use of arrays spotted with 12 instead of 8 spot-pins). The contribution of dye-effects was determined to be only $4 \%$, which is low compared to the contribution of dye-effects determined for in studies from Chen et al. and Dombrowski et al. [18,24]. The latter study describes the use of a direct labeling kit. In contrast, indirect labeling was used in our study, in which differential hybridization of Cy3 and Cy5-labeled cDNA is anticipated. Direct-labeling adds, next to this differential hybridization, (i) preference of the reverse transcriptase enzyme for the Cy3 label and (ii) prolonged exposure to air and light of the dyes increasing the chance of oxidation and / or bleaching. The main contributing factors identified in this study are in agreement with a number of studies involving cDNA derived from eukaryotic tissue cultures $[18,19,25]$. In contrast to these studies, we were able to attribute a relatively large contribution of the total variance to specific sources of errors (67\%) because of the efficient design of the validation experiment described here. Since the contributions of day-to-day variation, DNA microarray batch differences, and the experimenter to the variance amounted up to $27 \%$, it can be concluded that even higher data-quality can be obtained when experiments are performed under identical conditions.

The ANOVA model used does not account for gene-togene variances. Additional variance analyses were performed with datasets of which the $10 \%$ most noisy genes (with highest CVs) were omitted. In these experiments, the relative contribution of the various factors identified above remained unchanged (results not shown), indicating that the proposed procedure is robust and that its results are not dependent on a relatively small portion of noisy genes.

In this paper, data from hybridizations with RNA derived from the same experimental conditions were used. To examine whether the probes used on the slides are correct and whether observed gene expression levels are accurate, experiments should be carried out which measure known differentially expressed genes. A number of such studies in which targets were identified by DNA-microarray experiments (e.g. on arginine and glucose metabolism and on nisin resistance development), and subsequently verified by alternative techniques (real-time PCR, gene knock-out and / or overexpression studies), have successfully been performed in our laboratory (results not shown).

The validation experiments described in this study were designed to be a "worst case scenario." Data quality proved to be good even though they were obtained at challenging conditions: (i) flask-grown cells, (ii) harvesting in a growth phase in which relatively large changes in gene-expressions occur, and (iii) change of factors (e.g. day). These factors represent the conditions under which DNA microarray experiments are performed in our laboratory. Another laboratory could have different factors and levels: e.g. only one researcher that performs the experiments or a different organism under study. Such a laboratory should perform the validation experiments to determine the contribution of the factors that play a role in their particular case. The results of clustering indicate that functionally related genes share specific behaviour across the validation experiments (Figure 3 ). The significant expression levels and relatively large fluctuations in ratios of the $\gamma b g, \gamma b j$, and $\gamma i a$ gene groups are probably due to biological variations (growth-phase and medium-batch related). Furthermore, one can conclude that data from even genes with very low expression can reveal interesting trends. By preserving the maximum amount of data, one might be able to discern more subtle differences in expression levels of genes with low expression.

\section{Conclusion}

In this paper a novel validation scheme was employed to assess data quality and sources of errors of DNA-microarrays. Even in the case that $90 \%$ of the data were preserved and the experiments were performed at challenging conditions, the coefficient of variance was at an acceptable 25 $\%$. Clustering experiments showed that trends could be detected from genes with very low expression. Using ANOVA, day-to-day as well as experimenter-dependent variances were found to contribute strongly to the variance, while dye and culturing contributions to the variance were relatively modest. The validation scheme thus allows determining conditions that could be used to obtain DNA-microarray data of improved quality.

\section{Methods \\ DNA-microarray experimental procedures}

DNA-microarrays were prepared from amplicons of 2108 genes in the genome of Lactococcus lactis ssp. lactis IL1403 (Genbank accession number NC_002662; its annotation is based on the B. subtilis genome, Genbank accession number NC_000964). Primers were designed to amplify unique regions of these genes [26]. Generation of the amplicons, slide spotting, slide treatment after spotting, and slide quality control were performed as described [4] with modifications (see protocols at supplementary website [21]). Samples for RNA isolation were taken by rapid sampling of exponentially growing cultures of L. lactis. Methods for cell disruption, RNA isolation, RNA quality control, complementary DNA (target) synthesis, indirect labeling, hybridization, and scanning are described in the supplementary web-site [21]. 


\section{Validation experiment}

The validation experiment (Figure 1) was designed as follows: two independent cultures of L. lactis ssp. lactis IL1403 were grown at $30^{\circ} \mathrm{C}$ to an optical density at 600 $\mathrm{nm}\left(\mathrm{OD}_{600}\right)$ of $2.0 / \mathrm{cm}$ (corresponding to end-log phase) in standing flasks with $50 \mathrm{~mL} \mathrm{M17} \mathrm{medium} \mathrm{[27]} \mathrm{contain-}$ ing $0.5 \%$ glucose $(\mathrm{w} / \mathrm{v})$. A $10 \mathrm{~mL}$ sample was taken from one of these cultures, while from the other culture two samples of $10 \mathrm{~mL}$ were withdrawn. For the validation experiments (supplementary Table S1 [21]), total RNA was extracted using the RNA isolation methods with and without macaloid, for slides made with 12 spot pins and 8 spot pins, respectively. The cDNAs were labeled according to the scheme in Figure 1. The mRNA derived from the A culture was labeled once with $\mathrm{Cy} 3$ and three times with the Cy5 dye. The mRNA derived from the $\mathrm{B}^{\mathrm{a}}$ and $\mathrm{B}^{\mathrm{b}}$ cultures were both labeled with the Cy3 dye. Finally, the labeled cDNAs were hybridized on L. lactis IL1403 DNAmicroarrays (Figure 1).

\section{Data processing}

Slide data were processed by using MicroPreP $[28,29]$. (i) spots that were bad (for instance due particles on the slide surface) were manually flagged (for an example see supplementary Figure S3 [21]). These flagged spots were deleted from the datasets because they yield unreliable measurements; (ii) since the spotting buffer contains small random DNA fragments, spots will always have a base signal, particularly in the $\mathrm{Cy} 3$ channel, due to autofluorensence of these fragments. The spot backgrounds in each grid for both channels were corrected for this autofluorescense by subtracting the intensity of the weakest spot; (iii) the $5 \%$ or $40 \%$ weakest spots (sum of Cy3 and Cy5 net signals) were deleted. The effect of filtering low-intensity spots from the datasets is demonstrated in supplementary Figure S4 [21]. The $5 \%$ cutoff was determined empirically: the most noisy data is removed from the datasets without removing reliable data; (iv) normalization was performed (the ratios were made comparable across slides) using a grid-based Lowess transformation [30] with $\mathrm{f}=0.5$ (fraction of genes to use); ( $\mathrm{v}$ ) for both channels the intensities of the "Lowess" fraction of genes were added to yield a total signal, and all intensities were divided by this total signal, yielding scaled, arbitrary expression levels. One has to bear in mind that the scaling procedure affects the signals, but not the ratios. Since the statistical procedures in this paper are based on the ratios, scaling does not affect these analyses; (vi) tables for variance analyses were made. These tables list for each measurement the factors and their levels (see also supplementary Table S1 [21]). For example: spot 1 of slide 1 of validation experiment 1 is gene $X$ (from the gene factor), was obtained by experimenter $\mathrm{Y}$ (from the factor experimenter), on day $\mathrm{Z}$ (from the factor day).
The scanned images, data, and experimental conditions were stored in the MIAME-compliant Molecular Genetics Information System (MolGenIS) [31].

\section{Statistical procedures and clustering}

The quality of the validation datasets discussed in this paper are presented by coefficient of variance (CV). CVs are calculated by dividing the standard deviation (SD) by the mean ratio of a gene and multiplying by $100 \%$. The minimum and maximum numbers of measurements for each gene were 13 and 54 (i.e. 9 validation experiments $\times$ 3 slides per validation experiment $\times 2$ technical replicates per slide), respectively. For single validation experiments, CVs and differential expression levels were determined for genes for which at least 4 measurements were available.

Differential expression tests were performed with the Cyber-T implementation of a variant of the t-test [32]. These tests yield for each gene the probability that it has a significantly different ratio than 1 . Due to that multiple tests for differential expressions were performed, the false discovery rate (FDR) was determined. The FDR represents the probability that a significant differentially expressed gene is in fact false-positive. FDRs were calculated by (i) ranking the genes by p-value, (ii) multiplying the p-values with the number of tests performed (similar to Bonferroni correction), and (iii) dividing by the number of genes with lower p-values. Genes were considered differentially expressed at both $\mathrm{p}<0.01$ and FDR $<0.01$.

The SDs of log (base 2)-transformed ratios were used for clustering purposes. The clustering technique groups genes which SDs are similar across the validation experiments. The values of SDs for genes with less than four measurements were interpolated by using the K-nearest two neighbours approach using Engene [33]: only four genes which lacked the first or last SD had to be omitted. For each gene, SDs were centered after which clustering was performed using the Kohonen self-organizing map (SOM) algorithm $(2 \times 2$ matrix $)$ in the Engene clustering package.

\section{ANOVA}

The statistical software package SPSS (version 11; SPSS Inc., Chicago, IL) was used to perform variance analyses (ANOVA). ANOVA determines the contributions of factors (e.g. day) and their levels (e.g. an experiment performed on Monday) to the total variance observed in the datasets. Supplementary Table S1 [21] presents factors and their levels used for ANOVA.

\section{ANOVA is robust with respect to violations}

The assumptions of ANOVA that (i) error variances are equal and (ii) the residuals of the model are normally distributed generally do not hold for DNA microarray data. 
However, the sole purpose of ANOVA for this paper was to estimate the relative contributions of the various factors, a purpose for which ANOVA is extremely robust. If the error variances are not equal, the estimators for the type III sums of squares of the various factors, although less efficient, are still valid and unbiased [34]. Furthermore, the efficiency reduces most when the ANOVA design is very unbalanced and/or random factors are implemented [35]. In our case, the design is quite balanced and a fixed-factors model is used. The relative sums of squares are used instead of p-values, because the latter might be violated by deviations from the assumptions.

A whole-slide model was chosen over a gene-by-gene model When performing variance analyses on DNA-microarray data, one can either use a whole-slide model or a more complicated model that allows for gene-to-gene differences. Gene-by-gene models can deal better with variances that are gene-dependent (due to differences in gene expression levels). However, as each of the three hybridized slides (Figure 1) contains different combinations of cDNAs derived from the A and B cultures, the gene expression levels are expected to differ from slide-to-slide, rendering the gene-by-gene method less effective than our whole-slide model.

\section{Genes were randomly selected for ANOVA}

The software could not handle a gene factor of 2108 levels (genes) and additional interactions in model (1). To reduce data dimensions, we chose to randomly select genes instead of other methods (e.g. grouping of genes based on clustering or function) because the latter depend on assumptions of which the validity for the datasets are difficult to determine. The selection was repeated 10 times (with $5 \%$ or 105 random genes each time) yielding 1050 genes of which 196 were drawn two or more times. These 854 uniquely selected genes (40.5\% of the total genes) corresponded well to the predicted $40.0 \%$ (calculated by $\left[1\right.$ - $\left.\left.\left(((2108-105) / 2108)^{10}\right)\right]\right)$. The sums of squares were averaged for the sources (i.e. factors) contributing significantly to the variance $(\alpha=0.05)$.

\section{The ANOVA model uses log-transformed ratio data}

Attempts to identify the sources of errors and their contributions to the variance based on signal data, proved to be unsuccessful due to large differences in gene expression levels. A similar observation has been made for oligonucleotide-based DNA-microarrays hybridized with liver tissue RNA [17]. For this reason, we used the following ANOVA model:

$$
\begin{aligned}
& r_{i g p b t v}=\mu+S_{i}+G_{g}+A_{a}+P_{p}+B_{b}+T_{t}+V_{v}+U_{u}+(V G)_{v g}+ \\
& (S G)_{i g}+(V S G)_{v i g}+\varepsilon_{i g p b t v}
\end{aligned}
$$

where $r_{i g p b t v}$ is the log (base 2)-transformed ratio of gene $g$, which is the $t^{\text {th }}$ replicate spot on slide $i$ performed by experimenter $p$ on array batch $b$ which was spotted with $u$ spot pins (either 8 or 12) in validation experiment $v . r_{i g p b t v}$ is determined by $\mu$ (the mean ratio across all the factors) and the global factors slide $(S)$, experimenter $(P)$, array batch $(B)$, day $(A)$, the validation experiment $(V)$, replicate spot $(T ; 1$ or 2$)$, the number of spot pins used $(U)$, and a residual error $\left(\varepsilon_{i g p b t v}\right)$. Dye-effects are assumed to be in the SG interaction: they are global although the relative contributions of slides $1-3$ might differ since only slide 1 contains a self-hybridization. The VSG interaction contains variances due to hybridization and sampling.

\section{Some factors are confounded}

Due to the fact that in our DNA-microarray laboratory validation experiments are only performed when necessary (i.e. to introduce a new scientist (experimenter) in the laboratory) confounding of some factors could not be avoided. Therefore, variance analyses were performed by employing the validation experiment $(V G)$ interaction which incorporates: experimenter $(P G)$, array batch $(B G)$, day $(A G)$, and the number of spot pins, coinciding with a change in RNA isolation method $(G U)$.

\section{Authors' contributions}

SvH, AdJ, RB, JK, and OK have designed the validation scheme. SvH, HK, NK, RL, and CdH have conducted the DNA-microarray experiments. SvH, AdJ, and CA analyzed the data and generated the figures. SvH, RB, AdJ, and CA drafted the paper. CA provided guidance with the statistical analysis. JK and $\mathrm{OK}$ critically read, revised and approved the final manuscript. All authors read and approved the final manuscript.

\section{Acknowledgements}

The authors would like to acknowledge Aldert Zomer, Wietske Pool, and Ite Teune for their valuable contributions and suggestions to this study. Work performed by SvH was supported by grant QLK3-CT-200I-0I473 under the EU programme 'Quality of life and management of living resources - the cell factory'. The work of RB, HK, and CdH was supported by SENTER, Ministry of Economic Affairs, in the form of a BTS project. The work of NK was supported by NWO-STW, grant 349-5257.

\section{References}

I. Schena M, Shalon D, Davis RW, Brown PO: Quantitative monitoring of gene expression patterns with a complementary DNA microarray. Science 1995, 270:467-470.

2. Shalon D, Smith SJ, Brown PO: A DNA microarray system for analyzing complex DNA samples using two-color fluorescent probe hybridization. Genome Res 1996, 6:639-645.

3. Stears RL, Martinsky T, Schena M: Trends in microarray analysis. Nat Med 2003, 9: 140-1 45.

4. Kuipers OP, de Jong A, Baerends RJ, Van Hijum SA, Zomer AL, Karsens HA, den Hengst CD, Kramer NE, Buist G, Kok J: Transcriptome analysis and related databases of Lactococcus lactis. Antonie Van Leeuwenhoek 2002, 82: I I3-I 22.

5. Bolotin A, Wincker P, Mauger S, Jaillon O, Malarme K, Weissenbach J, Ehrlich SD, Sorokin A: The complete genome sequence of the 
lactic acid bacterium Lactococcus lactis ssp. lactis ILI403. Genome Res 200I, II:73I-753.

6. Klaenhammer T, Altermann E, Arigoni F, Bolotin A, Breidt F, Broadbent J, Cano R, Chaillou S, Deutscher J, Gasson M, van de GM, Guzzo J, Hartke A, Hawkins T, Hols P, Hutkins R, Kleerebezem M, Kok J, Kuipers O, Lubbers M, Maguin E, McKay L, Mills D, Nauta A, Overbeek R, Pel H, Pridmore D, Saier M, van Sinderen D, Sorokin A, Steele J, O'Sullivan D, de Vos W, Weimer B, Zagorec M, Siezen R: Discovering lactic acid bacteria by genomics. Antonie Van Leeuwenhoek 2002, 82:29-58.

7. Kunst F, Ogasawara N, Moszer I, Albertini AM, Alloni G, Azevedo V, Bertero MG, Bessieres P, Bolotin A, Borchert S, Borriss R, Boursier L, Brans A, Braun M, Brignell SC, Bron S, Brouillet S, Bruschi CV, Caldwell B, Capuano V, Carter NM, Choi SK, Codani J], Connerton IF, Danchin $A, .:$ The complete genome sequence of the grampositive bacterium Bacillus subtilis. Nature 1997, 390:249-256.

8. Ivanova N, Sorokin A, Anderson I, Galleron N, Candelon B, Kapatral V, Bhattacharyya A, Reznik G, Mikhailova N, Lapidus A, Chu L, Mazur M, Goltsman E, Larsen N, D'Souza M, Walunas T, Grechkin Y, Pusch G, Haselkorn R, Fonstein M, Ehrlich SD, Overbeek R, Kyrpides N Genome sequence of Bacillus cereus and comparative analysis with Bacillus anthracis. Nature 2003, 423:87-9I.

9. Tettelin $\mathrm{H}$, Nelson KE, Paulsen IT, Eisen JA, Read TD, Peterson S, Heidelberg J, DeBoy RT, Haft DH, Dodson RJ, Durkin AS, Gwinn M, Kolonay JF, Nelson WC, Peterson JD, Umayam LA, White O, Salzberg SL, Lewis MR, Radune D, Holtzapple E, Khouri H, Wolf AM, Utterback TR, Hansen CL, McDonald LA, Feldblyum TV, Angiuoli S, Dickinson T, Hickey EK, Holt IE, Loftus BJ, Yang F, Smith HO, Venter JC, Dougherty BA, Morrison DA, Hollingshead SK, Fraser CM: Complete genome sequence of a virulent isolate of Streptococcus pneumoniae. Science 200I, 293:498-506.

10. Quackenbush J: Microarray data normalization and transformation. Nat Genet 2002, 32 Suppl:496-50I.

II. Benes V. Muckenthaler M: Standardization of protocols in cDNA microarray analysis. Trends Biochem Sci 2003, 28:244-249.

12. Fang Y, Brass A, Hoyle DC, Hayes A, Bashein A, Oliver SG, Waddington $D$, Rattray M: A model-based analysis of microarray experimental error and normalisation. Nucleic Acids Res 2003, 31 : e96.

13. Tilstone C: DNA microarrays: vital statistics. Nature 2003 , 424:610-612

14. Kerr MK, Churchill GA: Statistical design and the analysis of gene expression microarray data. Genet Res 200I, 77: 123-I28.

15. Kerr MK, Churchill GA: Experimental design for gene expression microarrays. Biostatistics 200I, 2: I83-20I.

16. Kerr MK, Martin M, Churchill GA: Analysis of variance for gene expression microarray data. J Comput Biol 2000, 7:819-837.

17. Spruill SE, Lu J, Hardy S, Weir B: Assessing sources of variability in microarray gene expression data. Biotechniques 2002, 33:916-3.

18. Chen J], Delongchamp RR, Tsai CA, Hsueh HM, Sistare F, Thompson $\mathrm{KL}$, Desai VG, Fuscoe JC: Analysis of variance components in gene expression data. Bioinformatics 2004, 20: I 436-I 446.

19. Tu Y, Stolovitzky G, Klein U: Quantitative noise analysis for gene expression microarray experiments. Proc Natl Acad Sci U SA 2002, 99:| |403|-| 4036.

20. Piper MD, Daran-Lapujade P, Bro C, Regenberg B, Knudsen S, Nielsen J, Pronk JT: Reproducibility of oligonucleotide microarray transcriptome analyses. An interlaboratory comparison using chemostat cultures of Saccharomyces cerevisiae. J Biol Chem 2002, 277:3700I-37008.

21. Molecular Genetics publications: supplementary data for a generally applicable validation scheme 2004 [http://mol gen.biol.rug.nl/publication/validation data].

22. Yuen T, Wurmbach E, Pfeffer RL, Ebersole BJ, Sealfon SC: Accuracy and calibration of commercial oligonucleotide and custom cDNA microarrays. Nucleic Acids Res 2002, 30:e48.

23. Baum M, Bielau S, Rittner N, Schmid K, Eggelbusch K, Dahms M, Schlauersbach A, TahedI H, Beier M, Guimil R, Scheffler M, Hermann C, Funk JM, Wixmerten A, Rebscher $H$, Honig M, Andreae C, Buchner D, Moschel E, Glathe A, Jager E, Thom M, Greil A, Bestvater F, Obermeier F, Burgmaier J, Thome K, Weichert S, Hein S, Binnewies T, Foitzik V, Muller M, Stahler CF, Stahler PF: Validation of a novel, fully integrated and flexible microarray benchtop facility for gene expression profiling. Nucleic Acids Res 2003, 3 I:e I5I.
24. Dombkowski AA, Thibodeau BJ, Starcevic SL, Novak RF: Gene-specific dye bias in microarray reference designs. FEBS Lett 2004 , 560:120-124.

25. Yue H, Eastman PS, Wang BB, Minor J, Doctolero MH, Nuttall RL, Stack R, Becker JW, Montgomery JR, Vainer M, Johnston R: An evaluation of the performance of CDNA microarrays for detecting changes in global mRNA expression. Nucleic Acids Res 200I, 29:E4I-E4I.

26. Van Hijum SAFT, de Jong A, Buist G, Kok J, Kuipers OP: UniFrag and GenomePrimer: selection of primers for genome-wide production of unique amplicons. Bioinformatics 2003, 19:1580-I582.

27. Terzaghi BE, Sandine WE: Improved medium for lactic streptococci and their bacteriophages. Appl Microbiol 1975, 29:807-8I3.

28. Van Hijum SAFT, García de la Nava J, Trelles O, Kok J, Kuipers OP. MicroPreP: a DNA microarray data preprocessing framework. Appl Bioinformatics 2003:24I-244.

29. García de la Nava J, Van Hijum SAFT, Trelles O: PreP: gene expression data pre-processing. Bioinformatics 2003, 19:2328-2329.

30. Yang YH, Dudoit S, Luu P, Lin DM, Peng V, Ngai J, Speed TP: Normalization for cDNA microarray data: a robust composite method addressing single and multiple slide systematic variation. Nucleic Acids Res 2002, 30:el5.

31. Swertz MA, De Brock EO, Van Hijum SA, de Jong A, Buist G, Baerends RJ, Kok J, Kuipers OP, Jansen RC: Molecular Genetics Information System (MOLGENIS): alternatives in developing local experimental genomics databases. Bioinformatics 2004, 20:2075-2083.

32. Long AD, Mangalam HJ, Chan BY, Tolleri L, Hatfield GW, Baldi P. Improved statistical inference from DNA microarray data using analysis of variance and a Bayesian statistical framework. Analysis of global gene expression in Escherichia coli KI 2. J Biol Chem 200I, 276:19937-19944.

33. García de la Nava J, Santaella DF, Alba JC, Carazo JM, Trelles O, Pascual-Montano A: Engene: the processing and exploratory analysis of gene expression data. Bioinformatics 2003, 19:657-658.

34. Kendall MG, Stuart A: The advanced theory of statistics Volume III. Fourth edition. London, Charles Griffin \& Company Ltd; 1983.

35. Scheffé H: Analysis of variance London, John Wiley and Sons; 1959. Publish with BioMed Central and every
scientist can read your work free of charge

"BioMed Central will be the most significant development for disseminating the results of biomedical research in our lifetime. "

Sir Paul Nurse, Cancer Research UK

Your research papers will be:

- available free of charge to the entire biomedical community

- peer reviewed and published immediately upon acceptance

- cited in PubMed and archived on PubMed Central

- yours - you keep the copyright
BioMedcentral 